\title{
Extra vascular lung water but not lung ultrasound predicts grade 3 pulmonary graft dysfunction and utilization of rescue therapies for severe hypoxemia after lung transplantation
}

\author{
C Guervilly $^{1 *}$, S Lehingue ${ }^{1}$, S Dizier ${ }^{1}$, L Zieleskiewics ${ }^{2}$, S Hraiech ${ }^{1}$, XB D'journo ${ }^{3}$, G Thomas ${ }^{1}$, F Klazen ${ }^{1}$, M Adda ${ }^{1}$, \\ A Roch', JM Forel' ${ }^{1}$, P Thomas ${ }^{3}$, M Leone ${ }^{2}$, L Papazian $^{1}$
}

From ESICM LIVES 2015

Berlin, Germany. 3-7 October 2015

\section{Intr}

Primary graft dysfunction (PGD) is the result of pulmonary edema following lung transplantation. The definition [1] is based on Pa02/Fi02 and the presence of lung infiltrates on chest X-ray. Lung ultrasonography (LUS) and the extravascular lung water index (EVLWi) are reliable methods for quantification of lung edema $[2,3]$.

\section{Objectives}

We tested if LUS and EVLWi were associated with grade 3 PGD.

\section{Methods}

We prospectively included patients who underwent lung transplantation in one university teaching hospital over a 14-month period. LUS scores and EVLWi were assessed at ICU admission and during the following 48 hours period. We compared patients with grade 3 PGD with the others.

\section{Results}

36 patients were included. Among them, 13 (36 \%) had grade 3 PGD. EVLWi was significantly higher in the grade 3 PGD group at ICU admission, day one and at day 2.

A cut-off value of $14 \mathrm{ml} / \mathrm{kg}$ of EVLWi at admission predicts the progression to grade 3 PGD with a sensitivity of $82 \%$ and a specificity of $77 \%$ and was significantly

${ }^{1}$ Respiratory Distress and Severe Infection Critical Care Unit, North Hospital, Assistance Publique-Hôpitaux de Marseille, Marseille, France

Full list of author information is available at the end of the article associated with the need for rescue therapy for severe hypoxemia.

Less than a half of patients had all their LUS windows available. LUS scores did not discriminate patients with grade 3 PGD from the others.

\section{Conclusions}

Contrary to LUS scores, EVLWi is a promising tool for early assessment of grade 3 PGD after lung transplantation.

\section{Authors' details}

${ }^{1}$ Respiratory Distress and Severe Infection Critical Care Unit, North Hospital, Assistance Publique-Hôpitaux de Marseille, Marseille, France. ${ }^{2}$ Department of Anesthesiology and Critical Care Medicine, North Hospital, Assistance Publique-Hôpitaux de Marseille, Marseille, France. ${ }^{3}$ Department of Thoracic Surgery and Diseases of the Esophagus, Aix-Marseille University, North Hospital, Assistance Publique-Hôpitaux de Marseille, Marseille, France.

Published: 1 October 2015

\section{References}

1. Christie JD, Carby M, Bag R, Corris P, Hertz M, Weill D: Report of the ISHLT Working Group on Primary Lung Graft Dysfunction part II: definition. A consensus statement of the International Society for Heart and Lung Transplantation. I Heart Lung Transplant Off Publ Int Soc Heart Transplant 2005, 24(10):1454-1459.

2. Agricola $E$, Bove T, Oppizzi M, et al: "ultrasound comet-tail images": A marker of pulmonary edema*: a comparative study with wedge pressure and extravascular lung water. Chest 2005, 127(5):1690-1695

3. Katzenelson R, Perel A, Berkenstadt $H$, et al: Accuracy of transpulmonary thermodilution versus gravimetric measurement of extravascular lung water. Crit Care Med 2004, 32(7):1550-1554.

doi:10.1186/2197-425X-3-S1-A233

Cite this article as: Guervilly et al:: Extra vascular lung water but not lung ultrasound predicts grade 3 pulmonary graft dysfunction and utilization of rescue therapies for severe hypoxemia after lung transplantation. Intensive Care Medicine Experimental 2015 3(Suppl 1):A233. (c) 2015 Guervilly et al.; This is an Open Access article distributed under the terms of the Creative Commons Attribution License (http:// creativecommons.org/licenses/by/4.0), which permits unrestricted use, distribution, and reproduction in any medium, provided the original work is properly cited. 